\title{
Effect of stocker management program on beef cattle skeletal muscle growth characteristics, satellite cell activity, and paracrine signaling impact on preadipocyte differentiation
}

\author{
Mathew A. Vaughn ${ }^{1}$, Phillip A. Lancaster ${ }^{2,3}$, Kelly C. Roden ${ }^{1}$, Evin D. Sharman², Clinton R. Krehbiel ${ }^{2}$, \\ Gerald W. Horn ${ }^{2}$ and Jessica D. Starkey ${ }^{1,4^{*}}$
}

\author{
${ }^{1}$ Texas Tech University Department of Animal and Food Sciences, Lubbock, TX 79409, USA \\ ${ }^{2}$ Oklahoma State University and Oklahoma Agricultural Experiment Station, Stillwater, OK 74078, USA \\ ${ }^{3}$ Missouri State University School of Agriculture, Springfield, MO 65897, USA \\ ${ }^{4}$ Auburn University Department of Poultry Science, Auburn, AL 36849, USA
}

\begin{abstract}
The objective of this study was to determine the effect of different stocker management programs on skeletal muscle development and growth characteristics, satellite cell (SC) activity in growing-finishing beef cattle as well as the effects of SC-conditioned media on preadipocyte gene expression and differentiation. Fall-weaned Angus steers $(n=76 ; 258 \pm 28 \mathrm{~kg})$ were randomly assigned to 1 of 4 stocker production systems: 1) grazing dormant native range (NR) supplemented with a $40 \%$ CP cottonseed meal-based supplement $\left(1.02 \mathrm{~kg} \cdot \mathrm{steer}^{-1} \cdot \mathrm{d}^{-1}\right)$ followed by long-season summer grazing (CON, $\left.0.46 \mathrm{~kg} / \mathrm{d}\right)$; 2) grazing dormant NR supplemented with a ground corn and soybean meal-based supplement fed at $1 \%$ of BW followed by short-season summer grazing (CORN, $0.61 \mathrm{~kg} / \mathrm{d}) ; 3)$ grazing winter wheat pasture (WP) at high stocking density $(3.21$ steers/ha) to achieve a moderate rate of gain (LGWP, $0.83 \mathrm{~kg} / \mathrm{d})$; and 4) grazing winter WP at low stocking density $(0.99$ steers $/ \mathrm{ha}$ ) to achieve a high rate of gain (HGWP, $1.29 \mathrm{~kg} / \mathrm{d}$ ). At the end of the stocker (intermediate harvest, $\mathrm{IH}$ ) and finishing (final harvest, $\mathrm{FH}$ ) phases, 4 steers / treatment were harvested and longissimus muscles (LM) sampled for cryohistological immunofluorescence analysis and SC culture assays. At IH, WP steers had greater LM fiber cross-sectional area than NR steers; however, at $\mathrm{FH}$, the opposite was observed $(p<0.0001)$. At IH, CORN steers had the lowest Myf-5+:Pax7+ SC density $(p=0.020)$, while LGWP steers had the most Pax7+ SC $(p=0.043)$. At FH, CON steers had the highest LM capillary density $(p=0.003)$ and their cultured SC differentiated more readily than all other treatments $(p=0.017)$. At FH, Pax7 mRNA was more abundant in $14 \mathrm{~d}$-old SC cultures from HGWP cattle $(p=0.03)$. Preadipocytes exposed to culture media from proliferating SC cultures from WP cattle isolated at FH had more PPARy $(p=0.037)$ and less FABP4 $(p=0.030)$ mRNA expression compared with NR cattle. These data suggest that different stocker management strategies can impact skeletal muscle growth, SC function, and potentially impact marbling development in growing-finishing beef cattle.

Keywords: Beef stocker cattle, Dormant native range, Marbling development, Satellite cell activity, Skeletal muscle growth, Winter wheat pasture
\end{abstract}

Received: Jun 30, 2019 Revised: Aug 8, 2019 Accepted: Aug 28,2019

"Corresponding author: Jessica D. Starkey, Auburn University Department of Poultry Science, Auburn, AL 36849, USA.

Tel: +1-334-703-8542, E-mail: jessica.starkey@auburn.edu

This is an Open Access article distributed under the terms of the Creative Commons Attribution Non-Commercial License (http://creativecommons.org/licenses/by$\mathrm{nc} / 4.0 /$ ) which permits unrestricted non-commercial use, distribution, and reproduction in any medium, provided the original work is properly cited.

Copyright (C) 2019 Korean Society of Animal Science and Technology. 


\section{Background}

Stocker production systems provide a useful tool to increase uniformity in BW and promote skeletal growth of small-framed beef cattle [1,2]. Millions of fall-weaned calves are wintered on dormant native range (NR) or winter wheat pasture (WP) in the Great Plains region of the United States every year. These two stocker production systems result in different rates of BW gain [3] and can ultimately influence feedlot performance and final quality grade [4]. Cattle fed lower concentrations of carbohydrates and allowed slower rates of BW gain exhibit greater proportions of type 1, oxidative skeletal muscle fibers at the expense of type 2, glycolytic fibers [5-9]. Both oxidative muscle fibers and intramuscular (IM) adipocytes are commonly found located near a well-developed vascular supply [10-13]. Within the perimysium, IM adipocytes develop in close proximity to muscle fibers and their resident muscle stem cells, called satellite cells (SC), which play a critical role in postnatal muscle growth [14,15]. This close spatial arrangement supports the possibility that marbling development could be directly influenced by skeletal muscle fibers, SC, or both through paracrine signaling mechanisms. We hypothesized that changes in the stocker management strategy including diet composition and rate of BW gain during the stocker phase would influence skeletal muscle metabolism, capillary development (angiogenesis), and SC mitotic activity as well as the skeletal muscle microenvironment to impact marbling. Our objective was to examine the effect of stocker management system and rate of BW gain during the stocker period on skeletal muscle growth characteristics, SC activity, and their subsequent paracrine signaling effects on preadipocyte differentiation and lipid filling in vitro.

\section{Materials and Methods}

Before the initiation of this research, all procedures relating to animal care, handling, and sampling were reviewed and approved by the Oklahoma State University Institutional Animal Care and Use Committee (AG-50-372 and AG-09-15).

\section{Animals and management}

A detailed description of the experimental procedures for the feeding and management portions of this study as well as stocker growth and feedlot performance and carcass characteristic data has been previously published in a companion paper (Exp. 2; [16]). Briefly, fall-weaned Angus steers ( $\mathrm{n}=76 ; 258 \pm 28 \mathrm{~kg} ; 265 \pm 20 \mathrm{~d}$ of age) from the Oklahoma State University cow herd were randomly assigned to 1 of 4 stocker production systems: 1) grazing dormant NR supplemented with a 40\% CP cottonseed mealbased supplement $\left(1.02 \mathrm{~kg} \cdot\right.$ steer $\left.^{-1} \cdot \mathrm{d}^{-1}\right)$ followed by long-season
(132 d) summer grazing (CON, $0.46 \mathrm{~kg} / \mathrm{d}) ; 2$ ) grazing dormant NR supplemented with a ground corn and soybean meal-based supplement fed at $1 \%$ of BW followed by short-season (50 d) summer grazing (CORN, $0.61 \mathrm{~kg} / \mathrm{d}) ; 3)$ grazing winter WP at high stocking density (3.21 steers/ha) to achieve a moderate rate of gain (LGWP, $0.83 \mathrm{~kg} / \mathrm{d}$ ); and 4) grazing winter WP at low stocking density ( 0.99 steers $/ \mathrm{ha}$ ) to achieve a high rate of gain (HGWP, $1.29 \mathrm{~kg} / \mathrm{d})$. Steers continued to graze until the average BW of the treatment group reached approximately $375 \mathrm{~kg}$. Steers were adapted to a common finishing diet and fed until they reached a backfat thickness of at least $1.18 \mathrm{~cm}$. At the conclusion of the stocker (intermediate harvest, $\mathrm{IH}$ ) and finishing phase (final harvest, $\mathrm{FH}$ ), 4 steers / treatment were transported to the Oklahoma State University Food and Agriculture Products Center for slaughter (total $\mathrm{n}$ $=32$ ). Steers were equally stratified across treatments by known sire when selecting steers for harvests to minimize genetic variation among stocker treatments.

\section{Cryohistological analysis}

Samples from the left longissimus muscle (LM) between the $9^{\text {th }}$ and $13^{\text {th }}$ ribs were collected from each steer and embedded in optimal cutting temperature compound (VWR International, West Chester, PA, USA) in metal molds on liquid nitrogen-cooled metal blocks and stored at $-80^{\circ} \mathrm{C}$ before cryosectioning. Serial, $10-\mu \mathrm{m}-$ thick sections were cut using a Leica CM 1950 and mounted on positively charged glass slides (Superfrost Plus; VWR International). Slides were stored at $-20^{\circ} \mathrm{C}$ until immunofluorescence (IF) staining could be performed.

\section{Immunofluorescence staining and antibodies}

Cryosections were fixed and stained as previously described $[17,18]$ with slight modifications. Cryosections were fixed in 4\% paraformaldehyde (4\% PFA; USB Corporation, Cleveland, OH, USA) in PBS (Invitrogen, Carlsbad, CA, USA) for $10 \mathrm{~min}$ at room temperature (RT), followed by a $10 \mathrm{~min}$ PBS rinse. Sections were incubated with 5\% horse serum (HS; Invitrogen), 2\% BSA (MP Biomedical, Solon, OH, USA), 0.2\% Triton-X100 (Thermo Fisher Scientific, Fairlawn, NJ, USA) in PBS for 30 min at RT to block non-specific antibody binding. Antibodies and their respective dilutions are described below. After blocking solution was removed, cryosections were incubated in primary and secondary antibodies for $1 \mathrm{~h}$ and $30 \mathrm{~min}$, respectively. Following both primary and secondary antibody exposure, sections were rinsed 3 times for 5 min each. Finally, cryosections were incubated in $1 \mu \mathrm{g} / \mathrm{mL}$ 4, 6 -diamidino-2-phenylindole (DAPI, Thermo Fisher Scientific) for 1 min followed by 2 brief PBS rinses. Slides were cover-slipped with mounting media (Aqua Mount; Lerner Laboratories, Pittsburgh, PA, USA) and thin glass cover slips (VWR International) and left 
to dry at $4^{\circ} \mathrm{C}$ overnight. All cryosections were analyzed within 48 $\mathrm{h}$ of IF staining.

SC cultures were IF stained following the procedure for cryosections described above with slight modifications [17]. After fixation, cultures used to assess $\mathrm{SC}$ activity were rinsed twice with PBS, incubated in $0.5 \%$ Triton-X100 in PBS for $10 \mathrm{~min}$, and then incubated for $7 \mathrm{~min}$ in $4 \mathrm{~N}$ hydrochloric acid (Thermo Fisher Scientific) before incubation in a blocking solution as described above. All SC cultures were stored in $1 \mathrm{~mL}$ of PBS and imaged within 48 $\mathrm{h}$ after IF staining.

Primary antibodies utilized for analysis of LM cryosections were mouse anti-chicken Pax7 hybridoma cell supernatant (Pax7; 1:10 dilution), mouse anti-type 1 Myosin hybridoma cell supernatant (BA-D5; 1:100 dilution), mouse anti-type 2 Myosin hybridoma cell supernatant (SC-71; 1:100 dilution; Developmental Studies Hybridoma Bank (DSHB), Iowa City, IA, USA), rabbit polyclonal anti-C-terminus human Myf-5 (1:100 dilution; Santa Cruz Biotechnology, Santa Cruz, CA, USA), and un-conjugated rabbit anti-Ulex Europaeus Agglutinin-1 (UEA; 1:50 dilution; EY Laboratories, San Mateo, CA, USA). Primary antibodies were detected using the following secondary antibodies at a 1:1,000 dilution: Alexa Fluor 488-conjugated goat anti-mouse IgG1, Alexa Fluor 488-conjugated goat anti-rabbit IgG heavy and light chain, Alexa Fluor 546-conjugated goat anti-mouse IgG1, and Alexa Fluor 633-conjugated goat-anti mouse IgG2b (Invitrogen).

$\mathrm{SC}$ cultures were stained with anti-Pax7 hybridoma cell supernatant (1:5 dilution) and rat IgG2a anti-BrdU (1:250 dilution; Santa Cruz Biotechnology). Differentiated SC cultures were IF stained with anti-Pax7 hybridoma cell supernatant (1:5 dilution; DSHB) and mouse anti-sarcomeric Myosin IgG2b hybridoma supernatant (MF-20; 1:5 dilution; DSHB). Primary antibodies were detected using Alexa Fluor 488-conjugated goat anti-mouse IgG1 and Alexa Fluor 546-conjugated goat anti-rat IgG2b (Invitrogen) secondary antibodies diluted 1:1,000.

\section{Microscopy and digital imaging}

Immunofluorescence-stained cryohistological slides were imaged at 200-fold magnification using an inverted fluorescence microscope (Nikon Eclipse, Ti-E; Nikon Instruments Inc., Melville, NY, USA) equipped with a UV light source (Nikon Intensilight Inc.; C-HGFIE). Images were captured with a CoolSnap ES2 monochrome camera and analyzed using NIS Elements Imaging software (Basic Research, 3.10; Nikon Instruments Inc.).

Five random images were taken of cryosections from the $\mathrm{LM}$ of each steer. The Myf-5+, Pax7+, and Myf-5+:Pax7+ SC populations in each image were identified, counted, and densities expressed on a square millimeter basis. The proportion of type 1 and type 2 muscle fibers was determined in every image for each steer. All UEA+ capillaries in each image were enumerated and densities expressed on a square millimeter basis. The cross-sectional area of each fiber in each image was measured using NIS Elements software (Nikon Instruments Inc.) and expressed on a square micron basis. The total number of DAPI-stained cells in each image was also enumerated to determine nuclear density on a square millimeter basis.

All digital photomicrographs of SC and preadipocyte cell cultures were taken and analyzed using the microscopy equipment described above equipped with extra-long working distance objectives. Ten representative images from each steer at each time point were taken at 200-fold magnification.

\section{Satellite cell isolation and culture}

$\mathrm{SC}$ were isolated from the $\mathrm{LM}$ of each steer at intermediate and FH using a previously described differential centrifugation method [19-21] with only minor modifications. A 200-g sample of the left LM from between the $9^{\text {th }}$ and $13^{\text {th }}$ ribs of each steer was excised, placed in a sterilized stainless-steel tray, and transported to the cell culture laboratory where all visible fat was removed under a laminar flow hood. Each LM sample was ground using a sterilized meat grinder and a total of $96 \mathrm{~g}$ of tissue was used for $\mathrm{SC}$ isolation. Ground muscle was incubated in Pronase (Calbiochem, San Diego, CA, USA) diluted to $1 \mu \mathrm{g} / \mathrm{mL}$ in Earle's Balanced Salt Solution supplemented $100 \mathrm{U}$ penicillin $/ \mathrm{mL}, 100 \mu \mathrm{g}$ streptomycin $/ \mathrm{mL}$, and $20 \mu \mathrm{g}$ of gentamicin $/ \mathrm{mL}(\mathrm{AB}+\mathrm{G}$; Invitrogen) for $40 \mathrm{~min}$ at $37^{\circ} \mathrm{C}$ with gentle mixing by hand every $10 \mathrm{~min}$. After differential centrifugation, pellets containing the mononucleated cells were resuspended in 10\% fetal bovine serum (FBS; HyClone, Logan, UT, USA) in Dulbecco's Modified Eagle Medium (DMEM; Invitrogen) warmed to $37^{\circ} \mathrm{C}$. Cell suspensions from all 3 rounds of differential centrifugation from each steer were combined and filtered with 100 and $40 \mu \mathrm{m}$ Steriflip filters (Millipore, Billerica, MA, USA) to remove any remaining tissue debris. The filtered cell suspension was centrifuged at 1,500 $\times \mathrm{g}$ and the resulting cell pellet was resuspended in cold $\left(4^{\circ} \mathrm{C}\right) 10 \%$ dimethylsulfoxide (Sigma Aldrich, St. Louis, MO, USA) in 10\% FBS in DMEM supplemented with $A B+G$, and then distributed evenly into Nunc cryotubes (Thermo Fisher Scientific) on ice. Cell suspensions enriched with $\mathrm{SC}$ were kept at $-80^{\circ} \mathrm{C}$ for $16 \mathrm{~h}$ and then stored in liquid nitrogen until analysis.

To determine the effect of stocker system on SC proliferative activity, $\mathrm{SC}$ isolated from steers harvested at the end of the stocker and finishing phases were plated at equal densities on 24-well tissue culture plates coated with growth factor reduced Matrigel (BD Biosciences, Bedford, MA, USA) diluted to $1 \mathrm{mg} / \mathrm{mL}$ in DMEM. Parallel cultures were grown for 24, 48, 72, and 96 h post-plating in 10\% FBS in DMEM containing Ab + G. All SC cultures were maintained in a water-saturated environment at $37^{\circ} \mathrm{C}$ with 
$5 \% \mathrm{CO}_{2}$ and received fresh media every $48 \mathrm{~h}$. To determine the proportion of mitotically active cells, SC cultures were incubated in media containing $1.5 \mathrm{mg} / \mathrm{mL}$ bromodeoxyuridine (BrdU; Invitrogen) for $2 \mathrm{~h}$ prior to fixation and IF staining for BrdU and Pax7 as described above. The total number of mitotically active SC (Pax7+;BrdU+) cells was determined and expressed as a proportion of total DAPI+ cells.

For analysis of differentiation (fusion) capacity, SC were plated at equal densities and grown on reduced growth factor Matrigel-coated 24-well plates in 10\% FBS in DMEM supplemented with $\mathrm{AB}+\mathrm{G}$ until the cultures reached confluence. Culture media was replaced every $48 \mathrm{~h}$. On d 8, the FBS concentration in the culture media was reduced to $2 \%$ and cultures were maintained for another $6 \mathrm{~d}$ to allow maximum differentiation to occur. On $\mathrm{d} 14$, SC cultures were fixed, IF stained, and imaged as described above. Differentiation capacity (fusion percentage) was determined by enumerating the total number of DAPI+ cells within sarcomeric Myosin+ multinucleated myotubes as a proportion of all DAPI+ cells/image.

Satellite cell culture RNA isolation and gene expression analysis

Total RNA was isolated from differentiated SC cultures $14 \mathrm{~d}$ post-plating. Total RNA was isolated using the Absolutely RNA Nanoprep Kit (Agilent Technologies, Santa Clara, CA, USA) per manufacturer's instructions including the on-column DNase treatment step to remove contaminating genomic DNA. Immediately after isolation total RNA was quantified using a spectrophotometer (Nanodrop-1000; Thermo Fisher Scientific) and stored at $-80^{\circ} \mathrm{C}$ until reverse transcription into cDNA and amplification was performed. Reverse transcription and amplification of $10 \mathrm{ng}$ of total RNA was performed using Quantitect Whole Transcriptome Kit (Qiagen; Valencia, CA, USA) following manufacturer's instructions for a high yield reaction. Immediately after reverse transcription and amplification, total cDNA was quantified using a spectrophotometer (Nanodrop-1000; Thermo Fisher Scientific) and samples were stored at $-20^{\circ} \mathrm{C}$ until gene expression analysis was performed.

Species and gene specific primers were designed using exonic sequences from Ensembl Genome Browser or National Center for Biotechnology Information (NCBI) using Primer3 software package [22]. Each primer was designed to be intron spanning to prevent amplification of contaminating genomic DNA. Specificity of each primer set was evaluated by comparing primer sequences to the database of GenBank using the blast tool (http://blast.ncbi. nlm.nih.gov/Blast.cgi). Complementarity of forward and reverse primer sequences for each primer pair was evaluated using OligoAnalyzer 3.1 (Integrated DNA Technologies, Coralville, IA, USA). Primers used for RT-PCR are listed in Table 1 including their accession number or the references from which they were ob-

Table 1. Primer sequences used for quantification of relative gene expression of satellite cell and 3T3-L1 preadipocyte cell cultures

\begin{tabular}{|c|c|c|c|c|c|}
\hline Gene & Accession or citation & & Primer sequence ( $5^{\prime}$ to $\left.3^{\prime}\right)$ & Product size (bp) & Annealing temp. $\left({ }^{\circ} \mathrm{C}\right)$ \\
\hline \multicolumn{6}{|l|}{ Satellite cell cultures } \\
\hline \multirow[t]{2}{*}{ Bovine $18 \mathrm{~S}$ rRNA ${ }^{1)}$} & DQ222453 & FWD & GACACGGACAGGATTGACAG & 243 & 60.0 \\
\hline & & REV & CGGACATCTAAGGGCATCAC & & \\
\hline \multirow[t]{2}{*}{ Pax7 } & ENSBTAT00000019924 & FWD & GGGCTCAGATGTGGAGTCAG & 85 & 57.0 \\
\hline & & REV & CATCTACACCCGAGAGGAGC & & \\
\hline \multirow[t]{2}{*}{ Myf-5 } & ENSBTAT00000038612 & FWD & CAGCGTCTACTGTCCTGATGT & 182 & 60.5 \\
\hline & & REV & TTCTCAАССTGCAАCTCCAG & & \\
\hline \multirow[t]{2}{*}{ Myogenin } & ENSBTAT00000007923 & FWD & СTCCCATAGCGCCTCCTG & 162 & 60.0 \\
\hline & & REV & CAGACGCCCACAATCTGC & & \\
\hline \multirow[t]{2}{*}{ Myostatin } & NM_001001525 & FWD & GTTTGGCTTGGCGTTACTCA & 178 & 60.0 \\
\hline & & REV & TTCCTTCTGCTCGCTGTTCT & & \\
\hline \multirow[t]{2}{*}{ IGF-1 } & NM_001077828 & FWD & АTCACATCCTCСТCGCATCT & 131 & 60.5 \\
\hline & & REV & CTGTCTCCGCACACGAACT & & \\
\hline \multicolumn{6}{|c|}{ 3T3-L1 preadipocyte cultures } \\
\hline \multirow[t]{2}{*}{ Bovine $18 \mathrm{~S}$ rRNA } & Granfar et al., 2005 & FWD & CTTAGAGGGACAAGTGGCG & 107 & 62.0 \\
\hline & & REV & ACGCTGAGCCAGTCAGTGTA & & \\
\hline \multirow[t]{2}{*}{ PPARY } & Taylor-Jones et al., 2002 & FWD & GCTGTTATGGGTGAAACTCTG & 351 & 60.0 \\
\hline & & REV & ATAAGGTGGAGATGCAGGTTC & & \\
\hline \multirow[t]{2}{*}{ FABP4 } & Guan et al., 2002 & FWD & GGGATTTGGTCACCATCCG & 204 & 60.0 \\
\hline & & REV & CCAGCTTGTCACCATCTCG & & \\
\hline
\end{tabular}




\section{JAST}

tained [23-25].

To quantify relative mRNA abundance, PCR reactions were performed using a Bio-Rad IQ5 Optical Detection system and software (BioRad Laboratories, Inc., Hercules, CA, USA). Reactions were mixed in 96-well plates with each well containing $7 \mu \mathrm{L}$ of RT2 SYBR Green Fluor FAST Mastermix (Qiagen), $0.23 \mu \mathrm{L}$ of a $25 \mu \mathrm{m}$ forward and reverse primer mix (Integrated DNA Technologies), $2.77 \mu \mathrm{L}$ PCR Certified Water (Teknova; Hollister, CA, USA), and $10 \mathrm{ng}$ of cDNA. Gene expression assays were performed using the following cycling conditions: a $10 \mathrm{~min}$ hold at $95^{\circ} \mathrm{C}$ and 40 cycles of $95^{\circ} \mathrm{C}$ for $10 \mathrm{~s}$, optimum annealing temperature for each primer set (Table 1) for $30 \mathrm{~s}$, with a $72^{\circ} \mathrm{C}$ extension for $30 \mathrm{~s}$. Following amplification, melt curve analysis was performed to verify the specificity of the reaction. For each gene, all reactions displayed a single melt peak temperature, indicating that a unique product was amplified. Bovine $18 \mathrm{~S}$ ribosomal RNA (B18S) was used as the reference gene for normalization. The relative quantification of mRNA expression was computed using the procedure as described previously [26]. Briefly, the threshold cycle $(\mathrm{Ct})$ values of each gene were converted to quantitative expression values relative to the sample with the lowest $\mathrm{Ct}$ value using the PCR reaction efficiency factor of each gene. The quantitative expression value was then divided by the quantitative expression value of $\mathrm{B} 18 \mathrm{~S}$ the reference gene to calculate normalized mRNA expression. This procedure allowed statistical analysis of linear mRNA expression values relative to B18S after adjusting for differences in reaction efficiency.

\section{Satellite cell-conditioned culture media and preadipo- cyte differentiation}

Embryonic mouse preadipocytes (3T3-L1; ATCC, Manassas, VA, USA) were plated at a density of $4.5 \times 10^{4} \mathrm{cells} / \mathrm{cm}^{2}$ and cultured for $6 \mathrm{~d}$ in $10 \%$ calf serum (CS; HyClone)/DMEM with $\mathrm{AB}+\mathrm{G}$. Culture media was changed every $48 \mathrm{~h}$. After $6 \mathrm{~d}$ in culture when 3T3-L1 preadipocytes were confluent, media was replaced with SC-conditioned media from either $96 \mathrm{~h}$ (proliferative) or $14 \mathrm{~d}$ (differentiated) SC cultures collected at $96 \mathrm{~h}$ and $14 \mathrm{~d}$ post-plating, respectively. After $48 \mathrm{~h}$ of exposure to SC-conditioned media, the 3T3-L1 preadipocyte cultures were fixed and stained with the neutral lipid marker, Oil red O (ORO; Sigma Aldrich) as previously described $[27,28]$. Cultures were incubated in the ORO staining solution for $2 \mathrm{~min}$ at RT, rinsed twice briefly in PBS, and incubated in DAPI for 1 min followed by 2 brief PBS rinses. The proportion of total DAPI+ 3T3-L1 preadipocytes exhibiting lipid accumulation and ORO positivity was determined.

Total RNA was isolated from 3T3-L1 preadipocytes cultures after $48 \mathrm{~h}$ of exposure to SC-conditioned media using the GE Healthcare RNA MiniSpin kit (Little Chalfont, Buckinghamshire,
UK) according to the manufacturer's instructions. Total RNA was quantified, reverse transcribed, and amplified exactly as described above for SC. Gene expression analysis was conducted as described above for $\mathrm{SC}$ except that $5 \mathrm{ng}$ of cDNA was used. Primers used for gene expression analysis of 3T3-L1 preadipocytes were obtained from the literature [23-25] and are listed in Table 1.

\section{Statistical analysis}

All data were analyzed using the GLIMMIX procedure of SAS (V9.2, SAS Institute, Inc., Cary, NC, USA). For all analyses, treatment was the fixed effect and the Satterthwaite adjustment was used to correct degrees of freedom. Steer $(n=4 /$ treatment $)$ served as the experimental unit for all analyses as all grazing steers consumed their individual maximum amount of forage each day during the stocker phase [16,29-31]. Proportional data such as $\%$ muscle fiber type, $\%$ proliferative SC, $\%$ SC fusion, and \% $\mathrm{ORO}+3 \mathrm{~T} 3-\mathrm{L} 1$ cells were subjected to analysis of variance using the events/experiments syntax for binomial distributions with an $\mathrm{R}$-side covariance structure. All continuous variables were subjected to analysis of variance using the least square means syntax for Gaussian distributions with an R-side covariance structure. Least square means were separated using the PDIFF option of SAS and considered significantly different when $p \leq 0.05$. Tendencies for differences among treatment least square means were declared when $0.0501 \leq p \leq 0.1000$.

\section{Results and Discussion}

Determining how stocker production program including differing diet composition and rate of BW gain during the stocker phase impacts skeletal muscle development and growth characteristics, SC activity, and the ability of factors released by beef cattle SC to influence preadipocyte differentiation in vitro were the objectives of this study.

\section{Longissimus muscle developmental and growth char- acteristics}

Intermediate Harvest. At the conclusion of the stocker phase, cattle that grazed winter WP and achieved the highest rates of BW gain $(\mathrm{HGWP}=1.29 \mathrm{~kg} / \mathrm{d}$ and LGWP $=0.83 \mathrm{~kg} / \mathrm{d})$ had greater LM skeletal muscle fiber cross-sectional area compared with cattle that grazed dormant NR and achieved lower rates of gain during the stocker phase $(\mathrm{CON}=0.46 \mathrm{~kg} / \mathrm{d}$ and $\mathrm{CORN}=0.61 \mathrm{~kg} / \mathrm{d} ; p<$ 0.0001; Table 2). Steers on the CON treatment that grazed dormant NR and had the lowest rate of BW gain during the stocker period tended to have more type 1 , oxidative muscle fibers $(p=$ $0.0572)$, fewer type 2 , glycolytic muscle fibers $(p=0.0572)$, and greater capillary density $(p=0.0781)$ in their LM at the conclusion 
Table 2. Skeletal muscle fiber cross-sectional area, fiber type, and capillary and nuclear density in the longissimus muscle of beef cattle from different stocker management programs at the conclusion of the stocker and finishing phases

\begin{tabular}{|c|c|c|c|c|c|c|}
\hline \multirow{2}{*}{ Variable } & \multicolumn{4}{|c|}{ Stocker management program } & \multirow{2}{*}{ SEM } & \multirow{2}{*}{$p$-value } \\
\hline & CON & CORN & LGWP & HGWP & & \\
\hline \multicolumn{7}{|l|}{ Intermediate harvest } \\
\hline Fiber area $\left(\mu m^{2}\right)$ & $1,902.06^{c}$ & $1,850.04^{c}$ & $2,458.69^{\mathrm{a}}$ & $2,159.87^{b}$ & 38.09 & $<0.0001$ \\
\hline Type 1 muscle fibers (\%) & $31.62^{x}$ & $28.01^{x y}$ & $26.79^{y}$ & $28.00^{x y}$ & 1.35 & 0.0572 \\
\hline Type 2 muscle fibers (\%) & $68.38^{x}$ & $71.99^{x y}$ & $73.21^{y}$ & $72.00^{x y}$ & 1.35 & 0.0572 \\
\hline Capillaries $/ \mathrm{mm}^{2}$ & $66.60^{x}$ & $49.40^{y}$ & $48.15^{y}$ & $58.55^{y}$ & 5.62 & 0.0781 \\
\hline Nuclei/mm² & 674.00 & 629.65 & 660.50 & 658.40 & 19.19 & 0.4234 \\
\hline \multicolumn{7}{|l|}{ Final harvest } \\
\hline Fiber area $\left(\mu \mathrm{m}^{2}\right)$ & $3,015.05^{b}$ & $3,209.15^{\mathrm{a}}$ & $2,927.39^{b}$ & $2,471.57^{\mathrm{c}}$ & 56.04 & $<0.0001$ \\
\hline Type 1 muscle fibers (\%) & $27.82^{x y}$ & $26.77^{y}$ & $31.13^{x}$ & $29.40^{x y}$ & 1.23 & 0.0720 \\
\hline Type 2 muscle fibers (\%) & $72.18^{x y}$ & $73.23^{y}$ & $68.87^{x}$ & $70.60^{x y}$ & 1.23 & 0.0720 \\
\hline Capillaries $/ \mathrm{mm}^{2}$ & $67.30^{\mathrm{a}}$ & $45.95^{b}$ & $41.30^{\mathrm{b}}$ & $50.05^{\mathrm{b}}$ & 5.10 & 0.0034 \\
\hline Nuclei/mm ${ }^{2}$ & $598.15^{\mathrm{a}}$ & $585.25^{\mathrm{ab}}$ & $542.95^{b}$ & $572.90^{\mathrm{ab}}$ & 18.41 & 0.1862 \\
\hline
\end{tabular}

a,b Least square means within a row lacking a common superscript differ $(p \leq 0.05)$.

${ }^{x, y}$ Least square means within a row lacking a common superscript tend to differ $(0.0501 \leq p \leq 0.10)$.

SEM, standard error of the LS mean.

CON, $40 \%$ crude protein cottonseed meal-based supplement on dormant native range; CORN, corn and soybean meal-based supplement on dormant native range; LGWP, reduced rate of gain on wheat pasture; HGWP: high rate of gain on wheat pasture.

of the stocker phase compared with cattle from all other treatments (Table 2). Nuclear densities in the LM of cattle from the 4 stocker programs were similar at $\mathrm{IH}(p=0.4234$; Table 2$)$. Densities of SC in the LM expressing only Myf-5 ( $p=0.87)$ did not differ among treatment (Table 3). However, at the conclusion of the stocker phase, steers that grazed NR assigned to the CORN treatment had the lowest densities of $\mathrm{Pax} 7+(p=0.0429)$ and Myf- $5+: \operatorname{Pax} 7+(p$ $=0.0203) \mathrm{SC}$ in their LM compared with steers from other treat ments (Table 3).

Final Harvest. At the conclusion of the finishing phase, LM fiber cross-sectional area was greatest in CORN steers that grazed NR during the stocker period compared with those that grazed winter WP at a high rate of gain (HGWP), with the CON and LGWP steers being similar and intermediate $(p<0.0001$; Table 2). Steers with the highest rate of gain during the stocker pe$\operatorname{riod}(\mathrm{HGWP} ; 1.29 \mathrm{~kg} \mathrm{BW}$ gain/d) had the smallest LM fiber cross-sectional area at $\mathrm{FH}(p<0.0001$; Table 2). By FH, the LM of $\mathrm{CON}$ steers had similar proportions of type 1 (oxidative) and type 2 (glycolytic) muscle fibers compared with all other treatments $(p$ $=0.0720$ ). Yet, at the end of the finishing phase, capillary density

Table 3. Skeletal muscle satellite cell densities in the longissimus muscle of beef cattle from different stocker management programs at the conclusion of the stocker and finishing phases

\begin{tabular}{|c|c|c|c|c|c|c|}
\hline \multirow{2}{*}{ Variable } & \multicolumn{4}{|c|}{ Stocker management program } & \multirow{2}{*}{ SEM } & \multirow{2}{*}{$p$-value } \\
\hline & CON & CORN & LGWP & HGWP & & \\
\hline \multicolumn{7}{|l|}{ Intermediate harvest } \\
\hline Myf-5+ cells $/ \mathrm{mm}^{2}$ & 80.95 & 88.90 & 85.50 & 81.85 & 6.32 & 0.8020 \\
\hline Pax7+ cells $/ \mathrm{mm}^{2}$ & $21.95^{\mathrm{ab}}$ & $17.40^{\mathrm{b}}$ & $25.35^{\mathrm{a}}$ & $20.15^{\mathrm{ab}}$ & 1.97 & 0.0429 \\
\hline Myf-5+:Pax7+ cells $/ \mathrm{mm}^{2}$ & $6.95^{\mathrm{a}}$ & $1.75^{\mathrm{b}}$ & $5.90^{\mathrm{a}}$ & $5.60^{\mathrm{a}}$ & 1.22 & 0.0203 \\
\hline \multicolumn{7}{|l|}{ Final harvest } \\
\hline Myf-5+ cells $/ \mathrm{mm}^{2}$ & 90.20 & 87.50 & 86.25 & 88.60 & 7.33 & 0.9841 \\
\hline Pax7+ cells $/ \mathrm{mm}^{2}$ & 17.65 & 21.35 & 21.70 & 20.35 & 3.17 & 0.7997 \\
\hline Myf-5+:Pax7+ cells $/ \mathrm{mm}^{2}$ & 5.15 & 4.50 & 5.20 & 4.90 & 1.34 & 0.9820 \\
\hline
\end{tabular}

a,beast square means within a row lacking a common superscript differ $(p \leq 0.05)$

SEM, standard error of the LS mean.

CON, $40 \%$ crude protein cottonseed meal-based supplement on dormant native range; CORN, corn and soybean meal-based supplement on dormant native range; LGWP, reduced rate of gain on wheat pasture; HGWP: high rate of gain on wheat pasture. 
remained greater in the slow-growing, $\mathrm{CON}$ steers compared with those from all other treatments ( $p=0.0034$; Table 2). After finishing, the LGWP steers had $4 \%$ more type 1 fibers in their LM ( $p$ $=0.0720)$ compared with CORN steers (Table 2). The densities of total nuclei $(p=0.1862$; Table 2$)$ and all SC populations evaluated (Pax7+, Myf-5+, and Pax7:Myf-5+) in the LM were similar ( $p \geq$ 0.7997; Table 3) among steers from different stocker production systems fed to a similar target backfat thickness.

The increase in oxidative muscle fiber types is consistent with what others have reported in cattle allowed reduced BW gain during the growing period $[6,12,13]$. At the conclusion of the finishing phase when cattle were fed to similar backfat thickness, the HGWP steers had the smallest LM areas and the highest USDA yield grades [16]. The reason for this is not apparent. Steers wintered on dormant NR supplemented with a followed by long-season summer grazing prior to finishing and allowed the lowest rates of BW gain during the stocker phase $(\mathrm{CON})$ tended to develop the most oxidative muscle fibers with the greatest capillary density by $\mathrm{IH}$ and maintained the increased capillary density through the FH [16]. The CON stocker management system also resulted in steers with the highest ADG and gain:feed ratio during the finishing phase and suggests there may be a compensatory gain effect in these slow-growing steers that entered the feedlot at heavier BW [29]. Collectively, these data support previous work showing that the rate of BW gain during the stocker phase can influence feedlot performance and final carcass characteristics [32,33]. Combined with previous reports, the results from this study indicate that slower rates of BW gain in beef cattle during the stocker phase may promote the development of a skeletal muscle environment rich in vascular supply that may enhance IM marbling development compared with stocker systems where high rates of BW gain are achieved.

\section{Skeletal muscle satellite cell activity in vitro}

Intermediate Harvest. The stocker treatment did not affect the proportion of Pax7+:BrdU+ SC observed at 24, 48, 72, or $96 \mathrm{~h}$ post-plating in $\mathrm{SC}$ cultures from steers isolated at the conclusion of the stocker phase ( $p \geq 0.1219$; Table 4$)$. Stocker management program also did not significantly alter the proportion of $\mathrm{SC}$ that fused into multi-nucleated myotubes in SC cultures isolated at $\mathrm{IH}(p=0.1570$; Table 5). The relative abundance of Pax7, Myf-5, Myogenin, Myostatin, and IGF-1 mRNA in $14 \mathrm{~d}$-old differentiated SC cultures was also similar among treatment $(p \geq 0.3370$; Table 5).

There was a marked increase in the density of $\mathrm{SC}$ co-expressing Pax7 and Myf-5 in the LM of CORN steers. Additionally, in culture SC from CORN steers at IH were the most proliferative $\mathrm{SC}$ at $96 \mathrm{~h}$ post-plating, and had the lowest fusion percentage at $14 \mathrm{~d}$ post-plating. Interestingly, their treatment counterparts ultimately went on to have the largest LM area at FH [16]. These data suggest that the CORN stocker management strategy may have resulted in greater $\mathrm{SC}$ proliferative capacity during the stocker phase and ultimately lead to enhanced SC-mediated hypertrophic growth of the LM after the cattle entered the feedyard for finishing. The reason for this apparent enhancement of what appears to be SC-mediated growth of LM fibers is not clear. It is possible that

Table 4. Mitotic activity over time in cultured skeletal muscle satellite cells of beef cattle from different stocker management programs at the conclusion of the stocker and finishing phases

\begin{tabular}{|c|c|c|c|c|c|c|}
\hline \multirow{2}{*}{ Variable } & \multicolumn{4}{|c|}{ Stocker management program } & \multirow{2}{*}{ SEM } & \multirow{2}{*}{$p$-value } \\
\hline & CON & CORN & LGWP & HGWP & & \\
\hline \multicolumn{7}{|l|}{ Intermediate harvest } \\
\hline \multicolumn{7}{|c|}{ Pax7+:BrdU+ cells $(\%)$} \\
\hline $24 \mathrm{~h}$ & 18.75 & 13.04 & 11.76 & 15.69 & 7.40 & 0.8772 \\
\hline $48 \mathrm{~h}$ & 17.86 & 22.58 & 19.23 & 24.44 & 7.84 & 0.9111 \\
\hline $72 \mathrm{~h}$ & 52.54 & 47.73 & 67.24 & 61.54 & 9.49 & 0.3897 \\
\hline $96 \mathrm{~h}$ & 61.04 & 80.95 & 77.78 & 63.33 & 7.65 & 0.1219 \\
\hline \multicolumn{7}{|l|}{ Final harvest } \\
\hline \multicolumn{7}{|c|}{ Pax7+:BrdU+ cells (\%) } \\
\hline $24 \mathrm{~h}$ & 4.76 & 22.58 & 11.11 & 11.54 & 8.66 & 0.4276 \\
\hline $48 \mathrm{~h}$ & 22.73 & 30.77 & 40.00 & 23.53 & 9.36 & 0.4503 \\
\hline $72 \mathrm{~h}$ & 53.57 & 52.50 & 46.15 & 55.00 & 11.56 & 0.9041 \\
\hline $96 \mathrm{~h}$ & 68.06 & 71.55 & 82.61 & 65.75 & 7.13 & 0.4683 \\
\hline
\end{tabular}

SEM, standard error of the LS mean.

CON, $40 \%$ crude protein cottonseed meal-based supplement on dormant native range; CORN, corn and soybean meal-based supplement on dormant native range; LGWP, reduced rate of gain on wheat pasture; HGWP, high rate of gain on wheat pasture. 
Table 5. Differentiation (fusion) capacity of cultured skeletal muscle satellite cells of beef cattle from different stocker management programs at the conclusion of the stocker and finishing phases

\begin{tabular}{|c|c|c|c|c|c|c|}
\hline \multirow{2}{*}{ Variable } & \multicolumn{4}{|c|}{ Stocker management program } & \multirow{2}{*}{ SEM } & \multirow{2}{*}{$p$-value } \\
\hline & CON & CORN & LGWP & HGWP & & \\
\hline \multicolumn{7}{|l|}{ Intermediate harvest } \\
\hline Fused, myotube nuclei $(\%)^{1)}$ & 20.49 & 12.90 & 14.23 & 17.40 & 3.03 & 0.1570 \\
\hline \multicolumn{7}{|l|}{ Final harvest } \\
\hline Fused, myotube nuclei $(\%)^{1)}$ & $26.95^{\mathrm{a}}$ & $18.71^{\mathrm{b}}$ & $15.38^{\mathrm{b}}$ & $17.67^{\mathrm{b}}$ & 3.10 & 0.0173 \\
\hline
\end{tabular}

${ }^{1)}$ Proportion of DAPI+ nuclei present inside sarcomeric Myosin+, multinucleated myotubes in $14 \mathrm{~d}$-old satellite cell cultures.

$a, b$ Least square means within a row lacking a common superscript differ $(p \leq 0.05)$.

SEM, standard error of the LS mean.

CON, $40 \%$ crude protein cottonseed meal-based supplement on dormant native range; CORN, corn and soybean meal-based supplement on dormant native range; LGWP, reduced rate of gain on wheat pasture; HGWP, high rate of gain on wheat pasture.

the combination of a higher starch content and lower overall gains of the CORN steers in the stocker phase stimulated IGF-1 production or increased blood glucose concentrations, which may help explain the differences in SC population heterogeneity (Table 3) in steers grazing NR compared with those entering the feedyard after high rates of gain during the stocker period (HGWP). Unfortunately, circulating blood glucose and IGF-1 concentrations were not measured on the cattle in this study; however, the data does provide a link between feeding regimen, $\mathrm{SC}$ transcriptional profile during the stocker period, and LM area at $\mathrm{FH}$, where the HGWP steers had the smallest LM areas and highest USDA yield grade of the 4 stocker programs [16].

Final Harvest. SC mitotic activity as indicated by the proportion of Pax7+:BrdU+ SC over time in culture was not different among treatment in cultures of SC collected at the conclusion of the finishing phase ( $p \geq 0.4276$; Table 4$)$. In contrast to IH, the fusion capacity of steers from the CON stocker treatment collected at FH was at least $8 \%$ greater than that of SC from steers subjected to the other 3 stocker management systems ( $p=0.0173$; Table 5). The relative expression of Myf-5, Myogenin, Myostatin, and IGF1 mRNA in differentiated SC cultures was not different among treatment ( $p \geq 0.2299$; Table 6). However, SC cultures collected at the end of the finishing phase from HGWP steers expressed more Pax7 mRNA after $14 \mathrm{~d}$ in culture compared with those from all other treatments $(p=0.03$; Table 6). The increased Pax7 mRNA abundance in differentiated SC cultures from steers on the

Table 6. Relative fold change in the expression of genes involved in myogenic regulatory pathways in differentiated (14 $\mathrm{d}$ in culture) skeletal muscle satellite cells of beef cattle from different stocker management programs at the conclusion of the stocker and finishing phases

\begin{tabular}{|c|c|c|c|c|c|c|}
\hline \multirow{2}{*}{ Variable } & \multicolumn{4}{|c|}{ Stocker management program } & \multirow{2}{*}{ SEM } & \multirow{2}{*}{$p$-value } \\
\hline & CON & CORN & LGWP & HGWP & & \\
\hline \multicolumn{7}{|l|}{ Intermediate harvest } \\
\hline Pax7 & 1.10 & 0.71 & 0.53 & 1.12 & 0.40 & 0.5801 \\
\hline Myf-5 & 1.23 & 1.92 & 1.22 & 2.19 & 0.49 & 0.3370 \\
\hline Myogenin & 1.83 & 1.74 & 1.86 & 1.41 & 0.43 & 0.8317 \\
\hline Myostatin & 0.03 & 0.45 & 0.18 & 0.09 & 0.25 & 0.5568 \\
\hline IGF-1 & 0.07 & 0.27 & 0.02 & 0.13 & 0.11 & 0.3491 \\
\hline \multicolumn{7}{|l|}{ Final harvest } \\
\hline Pax7 & $0.22^{b}$ & $0.34^{b}$ & $0.43^{b}$ & $2.29^{a}$ & 0.48 & 0.0312 \\
\hline Myf-5 & 1.14 & 1.04 & 1.74 & 1.98 & 0.35 & 0.2299 \\
\hline Myogenin & 1.82 & 2.44 & 1.46 & 2.31 & 0.50 & 0.5119 \\
\hline Myostatin & 0.56 & 0.79 & 0.08 & 0.26 & 0.39 & 0.5952 \\
\hline IGF-1 & 0.17 & 0.25 & 0.20 & 1.71 & 0.68 & 0.2643 \\
\hline
\end{tabular}

a,b Least square means within a row lacking a common superscript differ $(p \leq 0.05)$

SEM, standard error of the LS mean.

CON, $40 \%$ crude protein cottonseed meal-based supplement on dormant native range; CORN, corn and soybean meal-based supplement on dormant native range; LGWP, reduced rate of gain on wheat pasture; HGWP, high rate of gain on wheat pasture. 
HGWP stocker program may indicate that there were more active, unfused SC remaining in the culture after $14 \mathrm{~d}$. This phenomenon could indicate that the decreased LM area of the HGWP steers was a result of less SC mediated hypertrophy during the finishing period [16]. Combined, these data indicate that the stocker management program growing beef cattle are subjected to could alter the functionality and gene expression profiles of resident muscle $\mathrm{SC}$ populations and ultimately influence beef carcass characteristics, though the exact mechanisms of how this occurs are not yet clear.

\section{Satellite cell-conditioned media and 3T3-L1 preadipo- cyte differentiation}

Culture media from SC isolated from steers at the conclusion of the stocker and finishing phases was collected from proliferative $\mathrm{SC}$ at $96 \mathrm{~h}$ post-plating and differentiated SC cultures containing myotubes at $14 \mathrm{~d}$ post-plating. The $\mathrm{SC}$-conditioned media was then used to determine whether SC-produced molecules secreted into the media could influence the adipogenic gene expression and differentiation of mouse 3T3-L1 preadipocytes into lipid-filled, Oil Red O+ adipocytes.
Intermediate Harvest. The relative expression of peroxisome proliferator-activated receptor-gamma (PPAR $\gamma)$ and fatty acid binding protein 4 (FABP4) mRNA in 3T3-L1 mouse preadipocytes exposed to conditioned media from mitotically active or proliferative (96 h) SC cultures from steers at the conclusion of the stocker phase was not different among treatment ( $p \geq 0.4924$; Table 7). However, preadipocytes exposed to media collected from proliferative SC from CORN steers exhibited the most lipid accumulation $(\mathrm{ORO}+)$ and those exposed to media conditioned by $\mathrm{SC}$ harvested from the HGWP steers had the least $(p=0.0082$; Table 7). The relative expression of PPAR $\gamma$ and FABP 4 mRNA in preadipocytes exposed to conditioned media from differentiated (14 d) SC cultures from steers at the conclusion of the stocker phase were not different among treatment $(p \geq 0.1471$; Table 7$)$. However, the preadipocytes exposed to conditioned media from SC cultures from the HGWP steers had the least lipid accumulation as demonstrated by the lowest proportion of ORO+ cells and those exposed to the differentiated cultures from CORN and LGWP steers accumulated the most lipid ( $p=0.0470$; Table 7).

Final Harvest. Preadipocytes exposed to conditioned media from proliferative $(96 \mathrm{~h}) \mathrm{SC}$ isolated from HGWP steers had the

Table 7. Relative fold change in the expression of genes involved in adipogenic differentiation and lipid accumulation of 3T3-L1 preadipocytes exposed to conditioned media from mitotically active ( $96 \mathrm{~h}$ in culture) and differentiated (14 $\mathrm{d}$ in culture) satellite cells of beef cattle from different stocker management programs at the conclusion of the stocker and finishing phases

\begin{tabular}{|c|c|c|c|c|c|c|}
\hline \multirow{2}{*}{ Variable } & \multicolumn{4}{|c|}{ Stocker management program } & \multirow{2}{*}{ SEM } & \multirow{2}{*}{$p$-value } \\
\hline & CON & CORN & LGWP & HGWP & & \\
\hline \multicolumn{7}{|c|}{ Conditioned media from mitotically active satellite cells } \\
\hline \multicolumn{7}{|l|}{ Intermediate harvest } \\
\hline PPARY & 1.07 & 1.14 & 1.08 & 1.10 & 0.04 & 0.5405 \\
\hline FABP4 & 0.93 & 0.88 & 0.93 & 0.91 & 0.03 & 0.4924 \\
\hline Oil Red O+ cells (\%) & $52.43^{\mathrm{ab}}$ & $56.04^{\mathrm{a}}$ & $51.81^{\mathrm{ab}}$ & $47.7^{\mathrm{b}}$ & 1.73 & 0.0082 \\
\hline \multicolumn{7}{|l|}{ Final harvest } \\
\hline PPARY & $1.06^{b}$ & $1.06^{\mathrm{b}}$ & $1.09^{\mathrm{ab}}$ & $1.16^{\mathrm{a}}$ & 0.03 & 0.0370 \\
\hline FABP4 & $0.94^{\mathrm{a}}$ & $0.95^{\mathrm{a}}$ & $0.92^{\mathrm{ab}}$ & $0.86^{b}$ & 0.02 & 0.0295 \\
\hline Oil Red O+ cells (\%) & 57.12 & 56.35 & 53.56 & 54.02 & 1.50 & 0.2209 \\
\hline \multicolumn{7}{|c|}{ Conditioned media from differentiated satellite cells } \\
\hline \multicolumn{7}{|l|}{ Intermediate harvest } \\
\hline PPARY & 0.05 & 0.58 & 0.27 & 0.12 & 0.27 & 0.4666 \\
\hline FABP4 & 0.25 & 1.13 & 0.60 & 0.28 & 0.29 & 0.1471 \\
\hline Oil Red O+ cells (\%) & $72.09^{\mathrm{ab}}$ & $74.01^{\mathrm{a}}$ & $75.09^{\mathrm{a}}$ & $69.81^{\mathrm{b}}$ & 1.50 & 0.0470 \\
\hline \multicolumn{7}{|l|}{ Final harvest } \\
\hline PPARY & 0.19 & 0.65 & 0.04 & 0.45 & 0.33 & 0.4610 \\
\hline FABP4 & 0.82 & 1.24 & 0.44 & 0.65 & 0.24 & 0.1499 \\
\hline Oil Red O+ cells (\%) & $69.18^{\mathrm{ab}}$ & $71.68^{\mathrm{a}}$ & $65.99^{\mathrm{bc}}$ & $63.55^{\mathrm{c}}$ & 1.66 & 0.0027 \\
\hline
\end{tabular}

a-c Least square means within a row lacking a common superscript differ $(p \leq 0.05)$

SEM, standard error of the LS mean.

CON, $40 \%$ crude protein cottonseed meal-based supplement on dormant native range; CORN, corn and soybean meal-based supplement on dormant native range; LGWP, reduced rate of gain on wheat pasture; HGWP, high rate of gain on wheat pasture. 
highest relative expression of PPAR $\gamma$ mRNA $(p=0.0370)$ and lowest expression of FABP4 mRNA ( $p=0.0295$; Table 7$)$. Interestingly, the media from the active $\mathrm{SC}$ cultures from steers on the CORN stocker treatment had the opposite effect on the PPAR $\gamma$ and FABP4 expression of 3T3-L1 preadipocytes, although the proportion of $\mathrm{ORO}+$ cells was similar among all treatments $(p=$ 0.2209; Table 7).

Conditioned media from $14 \mathrm{~d}$-old differentiated SC cultures collected from steers at $\mathrm{FH}$ did not alter preadipocyte expression of either PPAR $\gamma$ or FABP4 ( $p \geq 0.1471)$. However, it did impact the proportion of lipid-filled $(\mathrm{ORO}+)$ cells. Preadipocytes exposed to the differentiated SC-conditioned media from HGWP steers exhibiting the fewest $\mathrm{ORO}+$ or lipid-filled cells and the media collected from CORN steer derived SC cultures inducing the most adipogenic differentiation as evidenced by the greatest proportion of ORO+ lipid-filled cells ( $p=0.0027$; Table 7).

$\operatorname{PPAR} \gamma$ is considered an early marker of adipogenesis while FABP4 is a commonly used marker of later adipogenic differentiation [34]. Therefore, the greater abundance of $\operatorname{PPAR} \gamma$ mRNA and decreased FABP4 mRNA expression observed in 3T3$\mathrm{L} 1$ preadipocytes exposed to $96 \mathrm{~h}-\mathrm{SC}$-conditioned media from HGWP steers indicates that these preadipocytes were not as far along in the adipogenic differentiation program compared with preadipocytes exposed to $\mathrm{SC}$-conditioned media from $\mathrm{CON}$ and CORN steers with LGWP steers being intermediate.

Cattle grazing WP have a 70\% lower acetate:propionate ratio compared with those grazing NR, which increases glucose availability compared to acetate [33]. It is known that IM adipocytes preferentially utilize glucose as the primary substrate for fatty acid synthesis [35]. Therefore, it is possible that the changes in acetate:propionate ratio during the stocker phase could alter IM adipocyte differentiation and have effects that last throughout the finishing phase. In addition, our previous work shows that the glucose-6-phosphate dehydrogenase (G6PDH) in the IM adipose tissue of HGWP cattle at the end of the finishing phase was significantly higher than that of LGWP cattle [31]. In addition, previous gene expression analysis work also suggests that there is a relationship between skeletal muscle growth rate and metabolism and IM tissue cellular differentiation and lipid synthesis [30]. Combined, these data support the notion that factors produced by skeletal muscle cells can influence adipogenic differentiation of mouse preadipocytes in vitro and could possibly influence beef cattle marbling development in vivo. Though determining exactly which signaling molecules the proliferative SC produced as well as the mechanism by which those products impacted the behavior of the preadipocytes will require further investigation. These data support the idea that skeletal muscle-derived factors can influence marbling adipocyte development and final carcass characteristics.
Overall, our results demonstrate that stocker management strategy and rate of BW gain during the stocker phase impact muscle fiber type and cross-sectional area, capillary density, as well as SC activity that may ultimately influence marbling development in growing beef cattle. In recent years, it has become clear that fetal nutrient availability impacts the metabolic profile of skeletal muscle, and results in life-long alternations in metabolism and growth [36,37]. Though this data indicates that stocker production regimen also programs later metabolism of beef cattle, some major questions remain regarding the cell signaling mechanisms responsible for the coordinated development of skeletal muscle and IM adipose tissue as well as how nutrition and management strategies imposed during the stocker phase can alter this relationship in growing beef cattle.

\section{Competing interests}

No potential conflict of interest relevant to this article was reported.

\section{Funding sources}

This work was supported in part by funds from the United States Beef Checkoff Program, the Agriculture and Food Research Initiative Special Grants numbers 2009-34198-19830 and 2010-3419820812, and the Agriculture and Food Research Initiative Grant number 2010-65206-20605 from the United States Department of Agriculture National Institute of Food and Agriculture.

\section{Acknowledgements}

The anti-sarcomeric Myosin hybridoma developed by D. A. Fischman, anti-Pax7 hybridoma developed by A. Kawakami, and anti-Myosin heavy chain type 1 and type 2A hybridomas developed by S. Schiaffino were obtained from the Developmental Studies Hybridoma Bank developed under the auspices of the NICHD and maintained by The University of Iowa, Department of Biology, Iowa City, IA 52242.

\section{Availability of data and material}

Upon reasonable request, the datasets of this study can be available from the corresponding author.

\section{Authors' contributions}

Conceptualization: Lancaster PA, Krehbiel CR, Horn GW, Starkey JD.

Data curation: Vaughn MA, Starkey JD.

Formal analysis: Vaughn MA, Lancaster PA, Starkey JD.

Methodology: Vaughn MA, Lancaster PA, Sharman ED, Horn

GW, Starkey JD.

Software: Vaughn MA, Starkey JD.

Validation: Vaughn MA, Starkey JD. 
Investigation: Vaughn MA, Lancaster PA, Roden K, Sharman ED, Horn GW, Starkey JD.

Writing - original draft: Vaughn MA, Starkey JD.

Writing - review \& editing: Vaughn MA, Lancaster PA, Roden KC, Sharman ED, Krehbiel CR, Horn GW, Starkey JD.

\section{Ethics approval and consent to participate}

Before the initiation of this research, all procedures relating to animal care, handling, and sampling were reviewed and approved by the Oklahoma State University Institutional Animal Care and Use Committee (AG-50-372 and AG-09-15).

\section{ORCID}

Mathew A. Vaughn

Phillip A. Lancaster

Kelly C. Roden

Evin D. Sharman

Clinton R. Krehbiel

Gerald W. Horn

Jessica D. Starkey

https://orcid.org/0000-0003-3812-5362 https://orcid.org/0000-0002-2871-6065 https://orcid.org/0000-0002-1281-8438 https://orcid.org/0000-0002-5776-5819 https://orcid.org/0000-0003-4470-7908 https://orcid.org/0000-0001-7524-5238 https://orcid.org/0000-0002-1565-5603

\section{References}

1. Anderson P. Optimum forage use in beef cattle growing and finishing diets. 1991. http://www.extension.umn.edu/beef/ components/publications/bcmu18.pdf. Accessed 23 Aug 2011.

2. Loken BA, Maddock RJ, Stamm MM, Schauer CS, Rush I, Quinn S, et al. Growing rate of gain on subsequent feedlot performance, meat, and carcass quality of beef steers. J Anim Sci. 2009;87:3791-7.

3. Hersom MJ, Horn GW, Krehbiel CR, Phillips WA. Effect of live weight gain of steers during winter grazing: I. feedlot performance, carcass characteristics, and body composition of beef steers.J Anim Sci. 2004;82:262-72.

4. Anderson P, Gleghorn J. Non-genetic factors that affect quality grade of fed cattle. In: Proceedings Beef Improvement Federation 39th Annual Research Symposium and Annual Meeting; 2007; Fort Collins, CO..

5. Seideman SC, Crouse JD. The effects of sex condition, genotype and diet on bovine muscle fiber characteristics. Meat Sci. 1986;17:55-72.

6. Vestergaard M, Therkildsen M, Henckel P, Jensen LR, Andersen HR, Sejrsen K. Influence of feeding intensity, grazing and finishing feeding on meat and eating quality of young bulls and the relationship between muscle fibre characteristics, fibre fragmentation and meat tenderness. Meat Sci. 2000;54:18795.

7. Lehnert SA, Byrne KA, Reverter A, Nattrass GS, Greenwood
PL, Wang YH, et al. Gene expression profiling of bovine skeletal muscle in response to and during recovery from chronic and severe undernutrition.J Anim Sci. 2006;84:3239-50.

8. Greenwood PL, Tomkins NW, Hunter RA, Allingham PG, Harden S, Harper GS. Bovine myofiber characteristics are influenced by postweaning nutrition. J Anim Sci. 2009;87:311423.

9. Shibata M, Matsumoto K, Oe M, Ohnishi-Kameyama M, Ojima K, Nakajima I, et al. Differential expression of the skeletal muscle proteome in grazed cattle. J Anim Sci. 2009;87:2700-8.

10. Blumer TN, Craig HB, Pierce EA, Smart WWG Jr, Wise MB. Nature and variability of marbling deposits in longissimus dorsi muscle of beef carcasses. J Anim Sci. 1962;21:93542.

11. Moody WG, Cassens RG. A quantitative and morphological study of bovine longissimus fat cells. J Food Sci. 1968;33:4752.

12. Melton C, Dikeman M, Tuma HJ, Schalles RR. Histological relationships of muscle biopsies to bovine meat quality and carcass composition. J Anim Sci. 1974;38:24-31.

13. Melton CC, Dikeman ME, Tuma HJ, Kropf DH. Histochemical relationships of muscle biopsies with bovine muscle quality and composition.J Anim Sci. 1975;40:451-6.

14. Moss FP, Leblond CP. Satellite cells as the source of nuclei in muscles of growing rats. Anat Rec. 1971;170:421-35.

15. Harper GS, Pethick DW. How might marbling begin? Austr J Exp Ag. 2004;44:653-62.

16. Sharman ED, Lancaster PA, McMurphy CP, Garmyn AJ, Pye BJ, Mafi GG, et al. Effect of rate of body weight gain in steers during the stocker phase. I. growth, partitioning of fat among depots, and carcass characteristics of growing-finishing beef cattle. J Anim Sci. 2013;91:4322-35.

17. Day K, Paterson B, Yablonka-Reuveni Z. A distinct profile of myogenic regulatory factor detection within Pax7+ cells at $\mathrm{S}$ phase supports a unique role of Myf5 during posthatch chicken myogenesis. Dev Dyn. 2009;238:1001-9.

18. Day K, Shefer G, Richardson JB, Enikolopov G, Yablonka-Reuveni Z. Nestin-GFP reporter expression defines the quiescent state of skeletal muscle satellite cells. Dev Biol. 2007;304:246-59.

19. Hathaway MR, Hembree JR, Pampusch MS, Dayton WR. Effect of transforming growth factor beta- 1 on ovine satellite cell proliferation and fusion. J Cell Physiol. 1991;146:435-41.

20. Frey RS, Johnson BJ, Hathaway MR, White ME, Dayton WR. Growth factor responsiveness of primary satellite cell cultures from steers implanted with trembolone acetate and estradiol-17beta. Basic Appl Myol. 1995;5:71-9. 
21. Johnson BJ, Halstead N, White ME, Hathaway MR, DiCostanzo A, Dayton WR. Activation state of muscle satellite cells isolated from steers implanted with a combined trenbolone acetate and estradiol implant.J Anim Sci. 1998;76:2779-86.

22. Rozen S, Skaletsky H. Primer3 on the WWW for general users and for biologist programmers. Methods Mol Biol. 2000;132:365-86.

23. Granfar RM, Day CJ, Kim MS, Morrison NA. Optimised real-time quantitative PCR assays for RANKL regulated genes. Mol Cell Probes. 2005;19:119-26.

24. Taylor-Jones JM, McGehee RE, Rando TA, Lecka-Czernik B, Lipschitz DA, Peterson CA. Activation of an adipogenic program in adult myoblasts with age. Mech Ageing Dev. 2002;123:649-61.

25. Guan Y, Taylor-Jones JM, Peterson CA, McGehee RE Jr. p130/p107 expression distinguishes adipogenic potential in primary myoblasts based on age. Biochem Biophys Res Comm. 2002;296:1340-5.

26. Vandesompele J, De Preter K, Pattyn F, Poppe B, Van Roy N, De Paepe A, et al. Accurate normalization of real-time quantitative RT-PCR data by geometric averaging of multiple internal control genes. Genome Biol. 2002;3:research0034.

27. Koopman R, Schaart G, Hesselink MK. Optimisation of oil red $\mathrm{O}$ staining permits combination with immunofluorescence and automated quantification of lipids. Histochem Cell Biol. 2001;116:63-8.

28. Starkey JD, Yamamoto M, Yamamoto S, Goldhamer DJ. Skeletal muscle satellite cells are committed to myogenesis and do not spontaneously adopt nonmyogenic fates. J Histochem Cytochem. 2011;59:33-46.

29. Sharman ED, Lancaster PA, McMurphy CP, Mafi GG, Starkey JD, Krehbiel CR, et al. Effect of rate of body weight gain of steers during the stocker phase. II. visceral organ mass and body composition of growing-finishing beef cattle.J Anim Sci.
2013;91:2355-66.

30. Lancaster PA, Sharman ED, Horn GW, Krehbiel CR, Starkey JD. Effect of rate of weight gain of steers during the stocker phase. III. gene expression of adipose tissues and skeletal muscle in growing-finishing beef cattle.J Anim Sci. 2014;92:146272.

31. Lancaster PA, Sharman ED, Horn GW, Krehbiel CR, Dillwith JW, Starkey JD. Effect of rate of weight gain of steers during the stocker phase. IV. rumen fermentation characteristics and expression of genes involved in substrate utilization for fatty acid synthesis in adipose tissues of growing-finishing beef cattle.J Anim Sci. 2015;93:3055-65.

32. Ridenour KW, Kiesling HE, Lofgreen GP, Stiffler DM. Feedlot performance and carcass characteristics of beef steers grown and finished under different nutrition and management programs.J Anim Sci. 1982;54:1115-9.

33. Choat WT, Krehbiel CR, Duff GC, Kirksey RE, Lauriault LM, Rivera JD, et al. Influence of grazing dormant native range or winter wheat pasture on subsequent finishing cattle performance, carcass characteristics, and ruminal metabolism.J Anim Sci. 2003;81:3191-201.

34. Rosen ED, Walkey CJ, Puigserver P, Spiegelman BM. Transcriptional regulation of adipogenesis. Genes Dev. 2000;14:1293-307.

35. Smith SB, Crouse JD. Relative contributions of acetate, lactate and glucose to lipogenesis in bovine intramuscular and subcutaneous adipose tissue. J Nutr. 1984;114:792-800.

36. Yates DT, Macko AR, Nearing M, Chen X, Rhoads RP, Limesand SW. Developmental programming in response to intrauterine growth restriction impairs myoblast function and skeletal muscle metabolism.J Pregnancy. 2012;2012:631038.

37. Yan X, Zhu MJ, Dodson MV, Du M. Developmental programming of fetal skeletal muscle and adipose tissue development.J Genomics. 2013;1:29-38. 